\title{
Trans-sialidase and sialidase activities discriminate between morphologically indistinguishable trypanosomatids
}

\author{
Enrique MEDINA-ACOSTA ${ }^{1}$, Antonia M. R. FRANCO ${ }^{2}$, Ana Maria JANSEN ${ }^{1,3}$, Marcos SAMPOL ${ }^{2}$, Neuza NEVÉS $^{1,3}$, \\ Lain PONTES-DE-CARVALHO ${ }^{1.4}$, Gabriel GRIMALDI, $\mathrm{Jr}^{2}$ and Victor NUSSENZWEIG ${ }^{1}$ \\ 1 New York University Medical Center, Michael Heidelberger Division of Immunology, New York, USA \\ 2 Instituto Oswaldo Cruz, Rio de Janeiro, Brazil \\ 3 Instituto de Ciências da Saúde, UFBA, Brazil \\ ${ }^{4}$ Centro de Pesquisas Gonçalo Moniz, Fundaçao Oswaldo Cruz, Brazil
}

(Received June 2/August 12, 1994) - EJB 94 0795/4

\begin{abstract}
The expression of trans-sialidase and sialidase activities in the kinetoplastid protozoa was explored as a potential marker to discriminate between the morphologically indistinguishable flagellates isolated from human, insects and vertebrate reservoir hosts. By virtue of the differences observed in the ratios of these enzyme activities, a collection of 52 species and strains comprising the major taxa of these parasites could be separated into four expression types. Type-I parasites express comparable levels of both trans-sialidase and sialidase activities (Endotrypanum species and Trypanosoma lewisi). Type-II parasites express predominantly trans-sialidase activity (Trypanosoma cruzi and Trypanosoma conorhini).Type-III parasites express sialidase activity exclusively (Trypanosoma rangeli and Trypanosoma leeuwenhoeki). Type-IV parasites do not express either activity (Leishmania species and Trypanoplasma borreli). The measurement of trans-sialidase and sialidase activities thus permits the differentiation of parasites frequently found in the same insect vectors that are difficult to distinguish, such as $T$. cruzi and $T$. rangeli, or in the same sylvatic vertebrate and invertebrate hosts, such as Leishmania and Endotrypanum.
\end{abstract}

Trans-sialidases are a class of recently described cell-surface-exposed trans-glycosidases that differ from the Golgiassociated sialyltransferases in that they catalyze the transfer of $N$-acylneuraminate (sialic acid) residues from substrates other than cytidine monophosphate (CMP)-sialic acid to glycoproteins, glycolipids and polysaccharides. Like all transglycosidases, the trans-sialidases also exhibit hydrolase (i.e. sialidase/neuraminidase) activity in the absence of suitable acceptors.

Trans-sialidase activity was discovered in the protozoan parasite Trypanosoma cruzi (order Kinetoplastida, family Trypanosomatidae) [1-5], the agent of Chagas' disease in the American continent, and shortly after in their African counterparts Trypanosoma brucei ssp. [6, 7], the causative organisms of sleeping sickness in humans and of nagana in domestic mammals. Trans-sialidases are, however, not restricted to trypanosomes as they also occur in the non-pathogenic trypanosomatids of the genus Endotrypanum [8], and in the pathogenic fungus Pneumocystis carinii (L. Trimble, N. Pavia \& M. E. A. Pereira, unpublished results). Although unequivocal evidence for the specific biological roles of the trans-sialidases in these parasite systems is lacking, the $T$. cruzi trans-sialidase is believed to be involved in the process

Correspondence to V. Nussenzweig, Michael Heidelberger Division of Immunology, Department of Pathology, New York University, Medical Center, MSB Room 131, New York, NY 10016, USA Fax: +12122638179 .

Abbreviations. MeUmb-NeuAc, 2'(4-methylumbelliferyl)-D-Nacetylneuraminic acid.

Enzymes. Sialidase (EC 3.2.1.18); trans-sialidase. of invasion of mammalian cells [3, 4], in defense against complement attack [9], in the intracellular fate and survival of the parasite (reviewed in [10-14]).

Currently, it is difficult to discriminate between pathogenic and non-pathogenic trypanosomatids. Striking similarities at the morphological, molecular and biological levels exist between many trypanosomatids isolated from sylvatic insects and/or vertebrate reservoir hosts that make the identification of the medically important parasites demanding (reviewed in $[15,16])$. Moreover, the geographical distributions of the different vectors and vertebrate reservoirs overlap. For example, the neotropical tree sloths (Edentata; genera Choleopus and Bradypus), which are reservoirs of at least six Leishmania species pathogenic for humans (reviewed in [17]), are hosts of Endotrypanum (E. monterogeii and $E$. schaudinni; reviewed in [18]) and two Trypanosoma species (T. rangeli [19] and T. leeuwenhoeki [20]), none of which are pathogenic for humans. These parasites species have also been isolated from recently fed anthropophilic sandflies (Lutzomyia spp.) [19-24].

Endotrypanum parasites are unique among the Kinetoplastida in that they infect erythrocytes of the vertebrate host [18], but these forms are rare in naturally or experimentally infected sloths. Diagnosis usually relies on the examination of parasites from cultures or from sandflies, and those forms of the parasite are morphologically indistinguishable from the promastigotes of Leishmania [25, 26]. Similarly, T. cruzi and $T$. rangeli can be found in the same vertebrate and insect hosts $[19,27,28]$. Although the blood-stage forms of $T$. rangeli differ morphologically, they are exceedingly rare in 
the circulation in the large majority of the infected populations. In contrast, the parasites obtained from the gut of the vectors and from culture are not easily distinguishable solely on the basis of morphology.

Even though several methods have been proposed to discriminate these trypanosomatids [29-40], the general concensus is that they are cumbersome and not satisfactory, and that the definitive identification can be only attained by recombinant DNA procedures [41-45]. Here, we show that the measurement of sialidase and trans-sialidase activities also permits rapid diagnosis of culture forms of trypanosomatids of medical importance.

\section{MATERIALS AND METHODS}

\section{Parasites}

Identification of the isolates, their geographic origin and the source of the stocks used in this study, are given in Table 1. Unless otherwise indicated, parasites were grown at $25^{\circ} \mathrm{C}$ in Schneider's Drosophila medium [46] supplemented with $20 \%$ heat-inactivated fetal bovine serum. T. cruzi and T. rangeli were cultured as described previously [47]. Trypanosoma lewisi was grown in Sprague-Dawley weaning rats that received a $0.5-\mathrm{ml}$ inoculum from a frozen sample (provided by J. Bienen and A. Clarkson, Jr, NYU Medical Center, USA) by intraperitoneal injection. Bloodstream forms were isolated from freshly drawn blood (4 days after infection) by centrifugation through a Ficoll:Paque (Pharmacia) cushion layer, as recommended by the manufacturer for the in vitro isolation of lymphocytes. Parasites (50\%) were recovered from the interphase (lymphocyte layer) or the Ficoll-Paque phase $(45 \%)$ ). For the isolation of the contaminant $T$. cruzi strain in the T. rangeli San Agustin strain, four two-monthold Swiss-background nude mice (nu/nu, Taconic) were inoculated intraperitoneally with $5 \times 10^{7}$ parasites obtained from in vitro cultures. Blood samples were collected every two days and screened fresh for the presence of parasites. Blood smears were stained with Giemsa. Infection of LLC-MK cells was carried out as described by Schenkman et al. [47].

\section{Sample preparation}

Cells $\left(1.5 \mathrm{ml} 1 \times 10^{7}-1 \times 10^{8}\right.$ cells $\mathrm{ml}^{-1}$, from 5-8-dayold cultures) were harvested in Eppendorf tubes by centrifugation at $1360 \times \mathrm{g}$ for $15 \mathrm{~min}$ at $4^{\circ} \mathrm{C}$ and washed once with ice-cold phosphate-buffered saline $(0.15 \mathrm{M} \mathrm{NaCl}, 0.01 \mathrm{M}$ sodium phosphate, $\mathrm{pH}$ 7.4) before lysis. The corresponding culture supernatant was transferred to a fresh tube and cleared by centrifugation at $13000 \times \mathrm{g}$ for $30 \mathrm{~min}$ at $4^{\circ} \mathrm{C}$. The pelleted cells were suspended in lysis buffer $(100 \mathrm{mM}$ sodium acetate, $\mathrm{pH} 7.0$, containing $1.5 \%$ Nonidet P-40, $0.1 \mathrm{mM} \mathrm{N}$ tosyl-L-lysine chloromethane, $0.1 \mathrm{mM}$ phenylmethanesulfonyl fluoride and leupeptin at $25 \mu \mathrm{g} \mathrm{ml}^{-1}$ ), at $1 \times 10^{8}$ cells $\mathrm{ml}^{-1}$, by vigorous vortexing followed by a 60 -min incubation on ice. Lysates were cleared by centrifugation at $13000 \times g$ for $30 \mathrm{~min}$ at $4^{\circ} \mathrm{C}$. Protein content was determined by the fluorescamine method, as described by Udenfriend et al. [48], using excitation at $350 \mathrm{~nm}$ and reading emission at $460 \mathrm{~nm}$ in a Titertek FluorosKan II (Flow Laboratories Inc., McLean, VA, USA). Peptides and polypeptides are known to yield maximum fluorescence near $\mathrm{pH} 7.0$, whereas for other reactive primary amines (amino acids, polyamines, etc.) fluorescence is generally maximal at $\mathrm{pH} 9.0$ with little fluorescence at $\mathrm{pH} 7.0$.

\section{Enzymic activities}

Sialidase activity was assayed by the hydrolysis of the fluorogenic substrate 2'(4-methylumbelliferyl)- $\alpha$-D $-N$-acetylneuraminic acid (MeUmb-NeuAc, Sigma) followed by quantification of the fluorescence emitted by methyl-umbelliferone, with excitation at $350 \mathrm{~nm}$ and reading emission at $460 \mathrm{~nm}$ in the Titertek FluorosKan II. The final reaction mixtures were $10 \mu \mathrm{l}$ lysate (regularly containing $10 \mu \mathrm{g}$ protein) and $40 \mu \mathrm{l} 1 \times$ substrate cocktail $[0.2 \mathrm{mM}$ MeUmb-NeuAc, $0.005 \%$ ultrapure bovine serum albumin (Boehringer Mannheim Corporation), in $100 \mathrm{mM}$ sodium acetate, $\mathrm{pH} 7.0 \mathrm{j}$ or $40 \mu \mathrm{l}$ supernatant and $10 \mu 15 \times$ substrate cocktail. Maximalactivity values were achieved after an overnight incubation in the dark, at room temperature. The overnight incubation did not increase the blank, background or noise values, which never exceeded a row value of 70 arbitrary fluorescence units. The blank row values were subtracted from the sample row values before normalization and calculation of the enzymic activity. The reaction conditions were determined experimentally to provide maximal activity values (i.e. highest sample versus blank ratios.) We have observed that the ratios of sialidase/trans-sialidase activities are maintained independently of the time length ( $45 \mathrm{~min}$ versus $16 \mathrm{~h}$ ) and/or temperature $\left(22^{\circ} \mathrm{C}\right.$ versus $\left.4^{\circ} \mathrm{C}\right)$ of incubation. The reactions were set up such that the measurements were maintained linear with a dynamic range of $1-1000$ pmol standard methyl-umbelliferone and, of $0.5-100 \mu \mathrm{g}$ protein lysate added. To ensure working under the linear range, we tested only $10 \mu \mathrm{g}$ protein. As monitored with standard solutions of methyl-umbellyferone, one fluorescence unit corresponded to one pmol methyl-umbellyferone. One unit sialidase activity is the amount of enzyme catalyzing the hydrolysis of $1 \mu \mathrm{mol}$ MeUmb-NeuAc/min $\left(1 \mathrm{U}=1 \mu \mathrm{mol} \cdot \mathrm{min}^{-1}\right)$.

Trans-sialidase activity was determined by the transfer of sialyl residues from 3 '-sialyllactose (donor/substrate) to [Dglucose- $\left.1-{ }^{14} \mathrm{C}\right]$ lactose (acceptor/substrate), in a 50- $\mu$ l reaction mixture containing $100 \mathrm{mM}$ sodium acetate, $\mathrm{pH} 7.0,50 \mathrm{nmol}$ sialyllactose and $370 \mathrm{pmol}(54 \mathrm{Ci} / \mathrm{mol})$ radioactive lactose. The mixture was incubated at room temperature for $45 \mathrm{~min}$. The reaction was then terminated by the addition of $1 \mathrm{ml}$ water and loaded onto a 1-ml QAE-Sephadex A50 column (Pharmacia LKB) equilibrated in water. The radioactive product (sialyl-[D-glucose-1 $\left.-{ }^{14} \mathrm{C}\right]$ lactose) was eluted with $1 \mathrm{ml} 1 \mathrm{M}$ ammonium formate, and quantified by liquid scintillation counting. One unit trans-sialidase activity is the amount of enzyme catalyzing the transfer of $1 \mu \mathrm{mol}$ sialic acid from sialyllactose to radiolabelled-lactose/min.

\section{DNA isolation and PCR amplification}

Genomic DNA was isolated using the TELT mini-prep method [49]. Diagnostic PCR amplification of the T. cruzi species-specific, repetitive, non-transcribed sequence SRE-1, was carried out as reported by Novak et al. [45].

\section{Statistical analysis}

The differences in enzyme activity ratios between the stocks were tested for statistical significance $(P<0.01)$ by the Student's $t$-test (two-tailed) assuming equal variances.

\section{RESULTS AND DISCUSSION}

We measured and compared the levels of sialidase and trans-sialidase activities from both cell extracts and culture 
Table 1. Origin and identification of the kinetoplastid reference strains, stocks and isolates employed in this study. Designations. $\mathrm{M}=$ Mammalia $; \mathrm{BRA}=$ Bradypus $; \mathrm{CHO}=$ Choloepus $; \mathrm{HOM}=$ Homo sapiens $; \mathrm{CEB}=$ Cebus apella $; \mathrm{I}=\mathrm{Insecta}: \mathrm{SHA}=$ Lutzomyia shanonni s.l. Data were acquired from the culture collections of ${ }^{1}$ J. J. Shaw, Instituto Evandro Chagas/Wellcome Parasitology Unit, Belém, PA, Brazil, ${ }^{2}$ M. P. Deane and ${ }^{3}$ A. M. R. Franco and G. Grimaldi Jr., Instituto Oswaldo Cruz/FIOCRUZ, Rio de Janeiro, RJ, Brazil, ${ }^{4}$ American Type Culture Collection, Rockville, MD. USA, ${ }^{5}$ A. H. C. S. Lopes, Instituto de Microbiologia/UFRJ, Rio de Janeiro, RJ, Brazil, ${ }^{6}$ T. V. Barrett, Instituto Nacional de Pesquisa da Amazonia, Manaus, AM, Brazil, ${ }^{7}$ E. S. Garcia, Instituto Oswaldo Cruz/FIOCRUZ, Rio de Janeiro, RJ, Brazil, ${ }^{8}$ P. Michels, ILP-TROP, Belgium, ${ }^{9}$ A. Clarkson, Jr., New York University, New York, USA. Stock identification of the Brazilian isolates was established by isoenzyme, monoclonal antibodies and molecular karyotype analyses (Franco, A. M. R., Momen, H. and Grimaldi, Jr. G., unpublished results).

\begin{tabular}{llll}
\hline Stock & Designation & Species & Locale \\
\hline Reference strains &
\end{tabular}

T01

T02

T05

T06

T07

T08

T09

T10

$\mathrm{T} 21$

$\mathrm{T} 22$

T23

$\mathrm{T} 24$

$\mathrm{T} 25$

T26

$\mathrm{H} 01$

L02

L03

E09

E11

E12

E49
MBRA/CO/00/BV $388^{\text {a }}$

$\mathrm{MCHO} / \mathrm{CO} / 00 / \mathrm{CH} 250^{\circ}$

MHOM/BR/00/F strain

Providencia

MPD

M238

ILP-TROP

30085-Y

SC-1

SC-58

SC-72

SC-61

San Agustin

T25 subclone

IMEG/US/72/H.meg

MHOM/BR/75/M4147

MCEB/BR/84/M8408

MBRA/PA/00/415P01 ${ }^{\mathrm{b}}$

MCHO/CR/62/A-9 ${ }^{\circ}$

MCHO/BR/88/M11602 d

$\mathrm{MCHO} / \mathrm{CO} / 68 / 473$

\section{Endotrypanum stocks}

\begin{tabular}{|c|c|}
\hline E08 & ISHA/BR/80/TM217 \\
\hline E10 & MBRA/PA/81/1222P82 \\
\hline E13 & $\mathrm{MCHO} / \mathrm{PA} / 79 / \mathrm{GML}-30^{\circ}$ \\
\hline E14 & $\mathrm{MCHO} / \mathrm{BR} / 80 / \mathrm{M} 6159^{\mathrm{d}}$ \\
\hline E15 & $\mathrm{MCHO} / \mathrm{BR} / 79 / \mathrm{M} 5725^{\mathrm{d}}$ \\
\hline E42 & MCHO/CR/00/LV88 ${ }^{\circ}$ \\
\hline E43 & $\mathrm{MCHO} / \mathrm{PA} / 00 / \mathrm{LV} 59^{\circ}$ \\
\hline E44 & $\mathrm{MCHO} / \mathrm{CO} / 00 / \mathrm{Col}^{\mathrm{d}}$ \\
\hline E45 & $\mathrm{MCHO} / \mathrm{PA} / 72 / 3130$ \\
\hline E46 & $\mathrm{MCHO} / \mathrm{CO} / 68 / 473$ \\
\hline E47 & $\mathrm{MCHO} / \mathrm{BR} / 80 / \mathrm{M} 6159^{\mathrm{d}}$ \\
\hline E48 & $\mathrm{MCHO} / \mathrm{BR} / 00 / \mathrm{LV}^{2} 6^{\mathrm{d}}$ \\
\hline
\end{tabular}

Brazilian isolates

\begin{tabular}{|c|c|}
\hline E01 & $\mathrm{MCHO} / \mathrm{BR} / 89 / \mathrm{RO} 9627^{\mathrm{e}}$ \\
\hline $\mathrm{E} 02$ & $\mathrm{MCHO} / \mathrm{BR} / 89 / \mathrm{RO} 1635^{\circ}$ \\
\hline E03 & MCHO/BR/89/RO1634 \\
\hline E04 & $\mathrm{MCHO} / \mathrm{BR} / 89 / \mathrm{RO} 1140^{\mathrm{e}}$ \\
\hline E05 & $\mathrm{MCHO} / \mathrm{BR} / 89 / \mathrm{RO} 1602^{\mathrm{e}}$ \\
\hline E06 & $\mathrm{MCHO} / \mathrm{BR} / 89 / \mathrm{RO} 1471^{\mathrm{e}}$ \\
\hline E07 & $\mathrm{MCHO} / \mathrm{BR} / 89 / \mathrm{RO} 1583^{\mathrm{e}}$ \\
\hline E16 & $\mathrm{MCHO} / \mathrm{BR} / 85 / \mathrm{IM} 2260^{\mathrm{d}}$ \\
\hline E17 & $\mathrm{MCHO} / \mathrm{BR} / 85 / \mathrm{IM} 2382^{\mathrm{e}}$ \\
\hline E18 & $\mathrm{MCHO} / \mathrm{BR} / 85 / \mathrm{IM} 2384^{\circ}$ \\
\hline E19 & $\mathrm{MCHO} / \mathrm{BR} / 85 / \mathrm{IM} 2389^{\mathrm{e}}$ \\
\hline E20 & $\mathrm{MCHO} / \mathrm{BR} / 85 / \mathrm{MM} 2404^{\mathrm{d}}$ \\
\hline E21 & $\mathrm{MCHO} / \mathrm{BR} / 89 / \mathrm{IM} 3605^{\mathrm{e}}$ \\
\hline E22 & $\mathrm{MCHO} / \mathrm{BR} / 89 / \mathrm{IM} 3606^{\mathrm{e}}$ \\
\hline E29 & ISHA/BR/80/IM1111 \\
\hline E31 & $\mathrm{MCHO} / \mathrm{BR} / 85 / \mathrm{IM} 2259^{d}$ \\
\hline $\mathrm{E} 32$ & $\mathrm{MCHO} / \mathrm{BR} / 85 / \mathrm{IM} 2380^{\circ}$ \\
\hline E33 & $\mathrm{MCHO} / \mathrm{BR} / 85 / \mathrm{IM} 2393^{\circ}$ \\
\hline E36 & $\mathrm{MCHO} / \mathrm{BR} / 89 / \mathrm{IM} 3603^{\mathrm{e}}$ \\
\hline
\end{tabular}

Trypanosoma leeuwenhoeki

T. leeuwenhoeki

T. cruzi

T. conorhini

T. conorhini

T. sp. (bat)

Trypanoplasma borreli

T. lewisi

T. rangeli

T. rangeli

T. rangeli

T. rangeli

T. rangeli

T. cruzi

Herpetomonas megaseliae

Leishmania guyanensis

L. shawi

Endotrypanum sp.

E. monterogeii

E. schaudinni

Endotrypanum sp.

E. schaudinni

Endotrypanum sp.

E. schaudinni

E. schaudinni

E. schaudinni

E. monterogeii

E. schaudinni

E. schaudinni

Endotrypanum sp.

Endotrypanum sp.

E. schaudinni

E. schaudinni

Endotrypanum sp.

Endotrypanum sp.

Endotrypanum sp.

Endotrypanum sp.

Endotrypanum sp.

Endotrypanum sp.

Endotrypanum sp.

Endotrypanum sp.

Endotrypanum sp.

Endotrypanum sp.

Endotrypanum sp.

Endotrypanum sp.

Endotrypanum sp.

Endotrypanum sp.

Endotrypanum sp.

Endotrypanum sp.

Endotrypanum sp.

Endotrypanum sp.

Endotrypanum sp.

$\begin{array}{ll}\text { Colombia } & 1 \\ \text { Colombia } & 1 \\ \text { Brazil } & 2 \\ \text { Brazil } & 2 \\ \text { Brazil } & 2 \\ \text { Brazil } & 2 \\ - & 8 \\ \text { U.S.A. } & 9 \\ \text { Brazil } & 7 \\ \text { Brazil } & 2 \\ \text { Brazil } & 2 \\ \text { Brazil } & 2 \\ \text { Brazil } & 2 \\ \text { U.S.A. } & - \\ \text { U.S.A. } & 2 \\ \text { Brazil } & 3 \\ \text { Brazil } & 3 \\ \text { Panama } & 1 \\ \text { Costa Rica } & 1 \\ \text { Brazil } & 1 \\ \text { Colombia } & 4\end{array}$

$\begin{array}{ll}\text { Brazil } & 2 \\ \text { Panama } & 1 \\ \text { Panama } & 1 \\ \text { Brazil } & 1 \\ \text { Brazil } & 1 \\ \text { Costa Rica } & 5 \\ \text { Panama } & 5 \\ \text { Colombia } & 5 \\ \text { Panama } & 5 \\ \text { Colombia } & 5 \\ \text { Brazil } & 5 \\ \text { Brazil } & 5\end{array}$

$\begin{array}{ll}\text { Rondonia } & 3 \\ \text { Rondonia } & 3 \\ \text { Rondonia } & 3 \\ \text { Rondonia } & 3 \\ \text { Rondonia } & 3 \\ \text { Rondonia } & 3 \\ \text { Rondonia } & 3 \\ \text { Pará } & 6 \\ \text { Rondonia } & 6 \\ \text { Rondonia } & 6 \\ \text { Rondonia } & 6 \\ \text { Amazonas } & 6 \\ \text { Rondonia } & 6 \\ \text { Rondonia } & 6 \\ \text { Amazonas } & 6 \\ \text { Pará } & 6 \\ \text { Rondonia } & 6 \\ \text { Rondonia } & 6 \\ \text { Rondonia } & 6\end{array}$

${ }^{\mathrm{a}}$ Host was B. tridactylus; ${ }^{\mathrm{b}}$ host was B. infuscatus; ${ }^{\mathrm{c}}$ host was $C$. hoffmanni; ${ }^{\mathrm{d}}$ host was $C$. didactylus; ${ }^{\mathrm{e}}$ host was $C$. juruanus. 
A

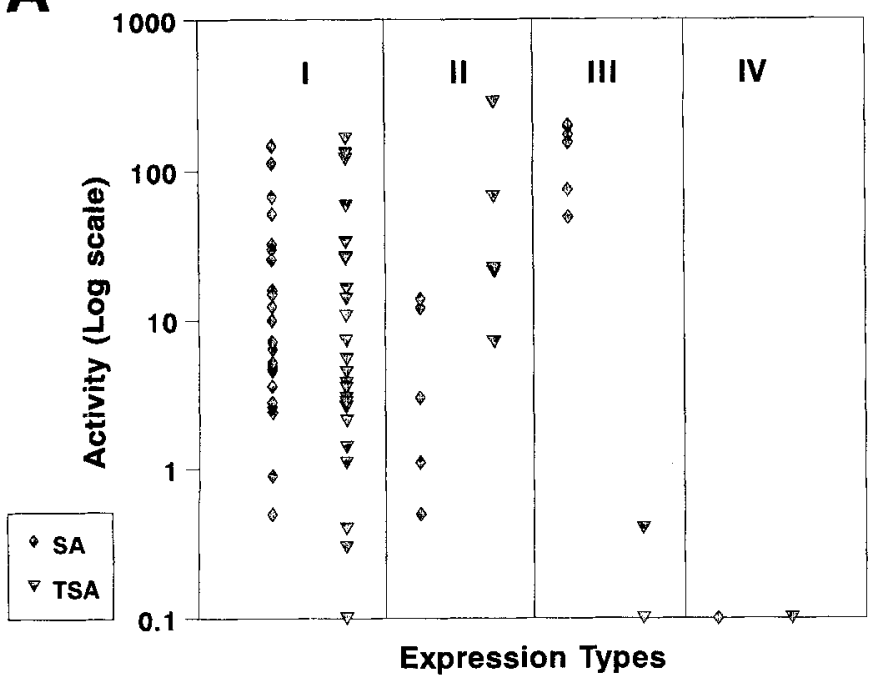

B

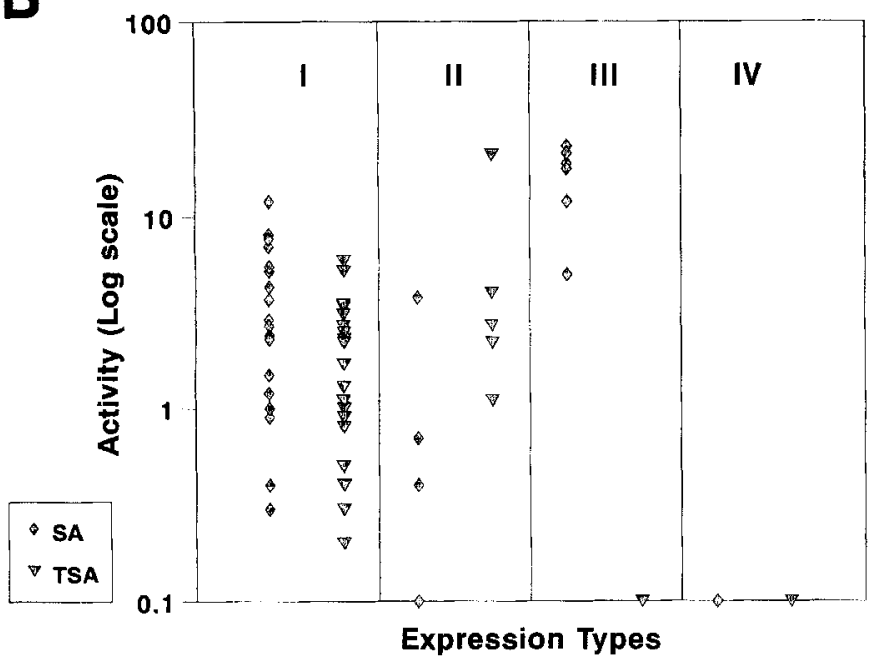

Fig. 1. Levels of sialidase (SA) and trans-sialidase (TSA) enzyme activities in cell lysates $(A)$ or culture supernatants $(B)$ of the kinetoplastids listed in Table 1. Shown is a distribution along the $y$-axis of the activity levels in the four (I-IV) parasite expression types. The $y$-axis is drawn in logarithmic scale. The relative enzymic activity in each sample is expressed as $\mu \mathrm{U} \mathrm{mg}_{\text {protein }}{ }^{-1}$. Each value represents the mean number of duplicates from one of three independent experiments. Variations between duplicates and experiments were less than $5 \%$.

supernatants of 52 parasite stocks comprising the two suborders of the kinetoplastida, Trypanosomatina (family Trypanosomatidae; genera Leishmania, Endotrypanum, Trypanosoma and Herpetomonas) and Bodonina (family Cryptobiidae; genus Trypanoplasma), Table 1. The stocks, which were originally isolated from different hosts (human, wild and domestic animals or sandflies) and geographic areas, were selected in order to represent the pathogenic and nonpathogenic parasites that are morphologically indistinguishable, i.e. within the genus Trypanosoma, we examined both pathogenic (T. cruzi) and non-pathogenic (T. lewisi [50], T. conorhini [51], T. rangeli and T. leeuwenhoeki) parasites.

Fig. 1 depicts the levels of enzymic activities present in cell extracts (A) and culture supernatants (B). The stocks fall into four expression types (I-IV), according to the sialidase/
Table 2. Sialidase and trans-sialidase expression types in culture forms of trypanosomatids. The activity ratios shown are from cell lysates. Within each expression type, the differences between the ratios from lysates and supernatants are not statistically significant $(t=P>0.1)$.

\begin{tabular}{|c|c|c|}
\hline Type & $\begin{array}{l}\text { Activity ratios } \\
\text { (sialidase/trans- } \\
\text { sialidase) }\end{array}$ & Parasite \\
\hline I $\quad A^{a}$ & $0.97 \pm 0.15$ & $\begin{array}{l}\text { Endotrypanum schaudinni } \\
\text { Endotrypanum spp. } \\
\text { Trypanosoma lewisi } \\
\text { E. monterogeii } \\
\text { E. schaudinni } \\
\text { Endotrypanum } \mathrm{spp} \text {. }\end{array}$ \\
\hline II & $0.10 \pm 0.06$ & $\begin{array}{l}\text { Trypanosoma cruzi } \\
\text { T. conorhini } \\
\text { Trypanosoma sp. (bat) }\end{array}$ \\
\hline III & $\begin{array}{c}74.7 / 0.0 \\
49.2 / 0.1 \\
180.3 \pm 18.0 / 0.0\end{array}$ & $\begin{array}{l}\text { T. leeuwenhoeki } \\
\text { T. leeuwenhoeki } \\
\text { T. rangeli }\end{array}$ \\
\hline IV & as in [8] & $\begin{array}{l}\text { Trypanoplasma borreli } \\
\text { Leishmania guyanensis } \\
\text { L. shawi } \\
\text { Herpetomonas megaseliae } \\
\text { L. mexicana, L. donovani, } \\
\text { L. major, L. chagasi, } \\
\text { L. amazonensis, } \\
\text { H. samuelpessoae, } \\
\text { Phytomonas davidi, } \\
\text { Leptomonas seymouri, } \\
\text { Crithidia fasciculata, } \\
\text { C. deanei, Blastocrithidia } \\
\quad \text { culicis }\end{array}$ \\
\hline
\end{tabular}

a The differences between the ratios in A and B are statistically significant $(t=P<0.01)$.

b Blood stages of the parasite (see Materials and Methods).

trans-sialidase enzyme activity ratios shown in Table 2 . Type I is represented by 23 Endotrypanum stocks, which express comparable levels of both activities. Two subgroups can be distinguished: (A) in which the activity ratios are $0.97 \pm 0.15$ (13 stocks), and (B) in which the ratios are 2.27 \pm 0.86 (11 stocks), Table 2. Note, in addition, that the absolute levels of enzymic activities within each subgroup vary greatly (from $0.1-164 \mu \mathrm{U} \cdot \mathrm{mg}^{-1}$ ), Fig. 1. The reason(s) for these variations is unknown. Artifacts such as differences in the growth stage of the parasites or proteolytic degradation of the enzyme during sample preparation are unlikely; all Endotrypanum extracts were prepared from 5-day-old cultures, and the ratios of the activities were remarkably constant, regardless of the incubation conditions (time length and temperature) of the assays. The marked differences in the levels of sialidase and trans-sialidase enzyme activities observed among the Endotrypanum stocks may be genetically determined and perhaps represent strain-specific traits of a species complex [18, 52]. The heterogeneity of Endotrypanum stocks was also noted by Franco et al. [36] who analyzed 27 of the 35 Endotrypanum stocks used here by isoenzyme electrophoresis. A comparison of the electrophoretic profiles with those from reference strains representing the genus revealed that the enzymic loci were highly polymorphic.

Type II includes T. cruzi and T. conorhini, which predominantly express trans-sialidase activity. The ratio of siali- 
dase/trans-sialidase activities in extracts or culture supernatants of these parasites is $0.1 \pm 0.06$.

Type III, represented by $T$. rangeli and $T$. leeuwenhoeki stocks, is characterized by high levels of sialidase activity and no, or very little, trans-sialidase activity. In stock T02, we consistently obtained $0.1 \mu \mathrm{U} \mathrm{mg}^{-1}$ trans-sialidase, a value which falls close to the sensitivity limit of the assay.

Type-IV parasites do not express either activity. Included in this category are the Leishmania species, Herpetomonas megaseliae, Trypanoplasma borreli and 11 stocks that were originally identified as Endotrypanum. These 11 stocks differ from the Endotrypanum reference strains by morphological, karyotypic, isoenzymic and in vitro growth rate criteria ([36], and Franco et al., unpublished observations). Moreover, two of these stocks (E46 and E47) came from reference strains that expressed both activities (E49 and E14, respectively). These observations argue against the authenticity of the nonexpressing stocks as belonging to the genus Endotrypanum, and suggest that the original stocks were contaminated or mislabelled.

In short, sialidase and trans-sialidase activities were detected in all reference Endotrypanum strains (Type I), independently of the reservoir host or the geographic area of isolation, while promastigotes of all Leishmania species examined ([8], and this report), including L. guyanensis (which shares with Endotrypanum spp. both the sloth and sandfly hosts), lack both activities (Type IV).

We have also extended the previous observations that the T. rangeli sialidase(s) lacks trans-sialidase activity [40, 53], while the $T$. cruzi enzyme exhibits both sialidase and transsialidase activities [5]. We assayed extracts of epimastigotes from five different strains of $T$. rangeli and found that they do not express detectable trans-sialidase activity.

The discriminatory power of the enzymic assays used here is best illustrated by the analysis of $T$. rangeli San Agustin strain (stock T25, Table 1). We found that stock T26 of this strain contained high levels of trans-sialidase activity and, suspecting contamination with $T$. cruzi, we performed several additional tests. Injection into nude mice yielded high levels of parasitemia, and the bloodstream trypomastigotes were morphologically indistinguishable from $T$. cruzi. This $T$. rangeli stock infected LLC-MK cells in vitro, and multiplied intracellularly as amastigotes. An axenic culture of the exiting trypomastigotes at $28^{\circ} \mathrm{C}$ did not contain the pleomorphic parasite population typical of $T$. rangeli stocks $\mathrm{T} 21-\mathrm{T} 24$, but was morphologically indistinguishable from $T$. cruzi. The bloodstream forms, the tissue-culture trypomastigotes and the epimastigote thus generated from strain T26, all expressed trans-sialidase activity. To confirm independently that these forms were $T$. cruzi, we carried out a differential PCR analysis. T. cruzi DNA was detected by amplification of the $T$. cruzi-specific ribosomal spacer repetitive element SRE-1 [45] which is absent in the genome of $T$. rangeli (not shown).

Our results are in good agreement with those reported by Schottelius [39] and Reuter et al. [40], who also distinguished $T$. rangeli from $T$. cruzi epimastigotes using a sialidase fluorescence test on culture supernatants. However, it should be noted that, unless cloning of the parasites is carried out, the fluorescence test cannot discriminate $T, c r u z i$ from $T$. rangeli in mixed infections or contaminated cultures, (i.e. high levels of sialidase activity reflect either the presence of $T$. rangeli exclusively or a mixed infection with $T$. cruzi). The measurement of trans-sialidase activity, as illustrated above, resolves this diagnostic problem.
An obvious point raised here that awaits further experimentation is the biological significance of the trans-sialidase activity in the culture forms of $T$. conorhini and $T$. leeuwenhoeki for which neither an intracellular lifestyle, nor a pathogenic activity in the mammalian hosts have been described. Similarly, both sialidase and trans-sialidase activities $(1: 1$ ratio) are expressed in the blood stages of $T$. lewisi, a rodent parasite that does not enter hosts cells.

Another important issue to be resolved is the sialylation states of the membrane glycoconjugates of Type-I parasites. It is conceivable that there is a dynamic equilibrium between the sialylated and desialylated states. In contrast, some of the surface components may not be accessible to the sialidase activity (if this is a separate enzyme) and they remain mostly sialylated in the presence of suitable donors.

Lastly, the lack of sialidase/trans-sialidase enzyme activities in the epimastigote forms of the cryptobiid $T$. borreli poses a challenging problem on the origin(s) of the trypanosomal enzymes. Current phylogenetic trees inferred from comparisons of nuclear small-subunit rRNA sequences from several kinetoplastids [54-58] indicate that $T$. borreli branches off early from the trypanosomatid lineage. Hence, the occurrence of the sialidase and trans-sialidase genetic information in the trypanosomes may have taken place after the separation of these lineages. Alternatively, the ancestor of $T$. borreli may have lost the information during evolution. Further comparative studies will be needed to address the antiquity of these enzymes and, in particular, whether or not they are present in the bodonids and the deeper rooted neighbours, the euglenoid flagellates.

We thank the providers of the various strains and stocks used in this study, listed in Table 1 . We are grateful to them for their generous donations. This work was supported by grants from the John D. and Catherine T. MacArthur Foundation and NIH (AI32966). We thank S. Paul and Chien-Kuo Lee for valuable suggestions on the manuscript.

\section{REFERENCES}

1. Previato, J. O., Andrade, A. F., Pessolani, M. C. \& MendoçaPreviato, L. (1985) Incorporation of sialic acid into Trypanosoma cruzi macromolecules. A proposal for a new metabolic route, Mol. Biochem. Parasitol. 16, 85-96.

2. Zingales, B., Carniol, C., de Lederkremer, R. M. \& Colli, W. (1987) Direct sialic acid transfer from a protein donor to glycolipids of trypomastigote forms of Trypanosoma cruzi, Mol. Biochem. Parasitol. 26, 135-144.

3. Piras, M. M., Henríquez, D. \& Piras, R. (1987) The effect of fetuin and other sialoglycoproteins on the in vitro penetration of Trypanosoma cruzi trypomastigotes into fibroblastic cells, Mol. Biochem. Parasitol. 22, 135-143.

4. Schenkman, S., Jiang. M.-S., Hart, G. W. \& Nussenzweig, V. (1991) A novel cell surface trans-sialidase of Trypanosoma cruzi generates a stage-specific epitope required for invasion of mammalian cells, Cell 65, 1117-1125.

5. Schenkman, S., Pontes de Carvalho, L. \& Nussenzweig, V. (1992) Trypanosoma cruzi trans-sialidase and neuraminidase activities can be mediated by the same enzymes, J. Exp. Med. $175,567-575$.

6. Pontes de Carvalho, L. C., Tomlinson, S., Vandekerckhove, F., Bienen, E., Clarkson, A. B., Jiang, M. S., Hart, G. M. \& Nussenzweig, V. (1993) Characterization of a novel trans-sialidase of Trypanosoma brucei procyclic trypomastigotes and identification of procyclin as the main sialic acid acceptor, $J$. Exp. Med. 177, 465-474.

7. Engstler, M., Reuter, G. \& Shauer, R. (1993) The developmentally regulated trans-sialidase from Trypanosoma brucei sialy- 
lates the procyclic acidic repetitive protein, Mol. Biochem. Parasitol. 61, 1-14.

8. Medina-Acosta, E., Paul, S., Tomlinson, S. \& Pontes-de-Carvalho, L. (1994) Combined occurrence of trypanosomal sialidase/trans-sialidase activities and leishmanial metalloproteinase gene homologues in Endotrypanum sp., Mol. Biochem. Parasitol.64, 273-282.

9. Tomlinson, S., Pontes-de-Carvalho, L. C., Vanderherkhove, F. \& Nussenzweig, V. (1994) The role of sialic acid in the resistance of Trypanosome cruzi trypomastigotes to complement, J. Immunol., in the press.

10. Cazzulo, J. J. \& Frasch, A. C. C. (1992) SAPA/trans-sialidase and cruzipain: two antigens from Trypanosoma cruzi contain immunodominant but enzymatically inactive domains, FASEB J. 6, 3259-3264.

11. Colli, W. (1993) Trans-sialidase: a unique enzyme activity discovered in the protozoan Trypanosoma cruzi, FASEB J. 7, $1257-1264$.

12. Schenkman, S. \& Eichinger, D. (1993) Trypanosoma cruzi trans-sialidase and cell invasion, Parasitol. Today 9, 218222.

13. Engstler, M. \& Schauer, R. (1993) Sialidases from African trypanosomes, Parasitol. Today 9, 222-225.

14. Schenkman, S., Eichinger, D., Pereira, M. E. A. \& Nussenzweig, V. (1994) Structural and functional properties of Trypanosoma trans-sialidase, Annu. Rev. Microbiol. 48, 499523.

15. Zeledón, R. (1974) Epidemiology, modes of transmission and reservoir host of Chagas' disease, in Trypanosomiasis and Leishmaniasis, Ciba Foundation Symposium 20, new series, pp. 51-85. Associated Scientific Publishers, Amsterdam.

16. Molyneux, D. H. \& Ashford, R. W. (1983) The biology of Trypanosoma and Leishmania, parasites of man and domestic animals, Taylor \& Francis Ltd., London.

17. Grimaldi, Jr., G. \& Tesh, R. B. (1993) Leishmaniases of the New World: Current concepts and implications for future research, Clin. Microbiol. Rev. 6, 230-250.

18. Shaw, J. J. (1992) Endotrypanum, a unique intraerythrocytic flagellate of New World tree sloths. An evolutionary link or an evolutionary backwater?, Ciência e Cultura 44, 107-116.

19. Miles, M. A., Arias, J. R., Valente, S. A., Naiff, R. D., de Souza, A. A., Póvoa, M. M., Lima, J. A. \& Cedillos, R. A. (1983) Vertebrate hosts and vectors of Trypanosoma rangeli in the Amazon Basin of Brazil, Am. J. Trop. Med. Hyg. 32, 12511259.

20. Travi, B. L., Zea, A. \& D'Alessandro, A. (1989) Trypanosoma (Herpetosoma) leeuwenhoeki in Choloepus hoffmani and Didelphis marsupialis of the Pacific Coast of Colombia, J. Parasitol. $75,218-224$.

21. Shaw, J. J. (1963) A possible vector of Endotrypanum schaudinni of sloth, Choleopus hoffmanni, in Panama, Nature 201, 417-418.

22. Christensen, H. A. \& Herrer, A. (1976) Neotropical sand flies (Diptera: Psychodidae), invertebrate hosts of Endotrypanum schaudinni (Kinetoplastida: Trypanosomatidae), J. Med. Entomol. 13, 299-303.

23. Christensen, H. A. \& de Vasquez, A. M. (1982) The treebuttress biotope: a pathobiocenose of Leishmania braziliensis, Am. J. Trop. Med. Hyg. 31, 243-251.

24. Arias, J. R., Miles, M. A., Naiff, R. D., Póvoa, M. M., de Freitas, R. A., Biancardi, C. B. \& Castellon, E. G. (1985) Flagellate infections of Brazilian sandflies (Diptera:Psychodidae): isolation in vitro and biochemical identification of Endotrypanum and Leishmania, Am. J. Trop. Med. Hyg. 34, 1098-1108.

25. Croft, S., Chance, M. \& Gardener, P. J. (1980) Ultrastructural and biochemical characterization of stocks of Endotrypanum, Ann. Trop. Med. Parasitol. 74, 585-589.

26. Soares, M. M., Lopes, A. H. C. S. \& de Sousa, W. (1990) Ultrastructural and steriological analysis of trypanosomatids of the genus Endotrypanum, Mem. Inst. Oswaldo Cruz 86, 175-180.

27. D'Alessandro, A. (1976) Biology of Trypanosoma (Herpetosoma) rangeli Tejera (1920) in Biology of Kinetoplastida,
(Lumsden, W. H. R. \& Evans, D. A., eds) vol. 1, pp. 327493, Academic Press, London.

28. Steindel, M., Carvalho Pinto, J. C., Toma, H. K., Mangia, R. H. R., Ribeiro-Rodrigues, R. \& Romanha, A. J. (1991) Trypanosoma rangeli (Tejera, 1920) isolated from a sylvatic rodent (Echimys dasythrix) in Santa Catarina Island, Santa Catarina State: First report of this trypanosome in the Southern Brazil, Mem. Inst. Oswaldo Cruz 86, 73-79.

29. Schottelius, J. (1982) Differentiation between Trypanosoma cruzi and $T$. rangeli by their different complement sensitivity, Tropenmed. Parasitol. 33, 147-150.

30. Schottelius, J. \& Muller, V. (1984) Interspecific differentiation of Trypanosoma cruzi, Trypanosoma conorhini and Trypanosoma rangeli by lectins in combinations complement lysis, Acta Trop. 41, 29-38.

31. Miranda Santos de, I. K. F. \& Pereira, M. E. A. (1984) Lectin discriminate between pathogenic and nonpathogenic South American trypanosomes, Am. J. Trop. Med. Hyg. 33, 839844.

32. Anthony, R. L., Williams, K. M., Sacci, J. B. \& Rubin, D. C. (1985) Subcellular and taxonomic specificity of monoclonal antibodies to New World Leishmania, Am. J. Trop. Med. Hyg. 34, 1085-1094.

33. Hudson, L., Guhl, F., Marinkelle, C. J. \& Rodriguez, J. (1987) Use of monoclonal antibodies for the differential detection of Trypanosoma cruzi and Trypanosoma rangeli in epidemiological studies and xenodiagnosis, Acta Trop. 44, 387-392.

34. Lopes A. H. \& McMahon-Pratt, D. (1989) Monoclonal antibodies specific for members of the genus Endotrypanum, $J$. Protozool. 36, 354-361.

35. Ebert, F. (1986) Isoenzymes of Trypanosoma rangeli stocks and their relation to other trypanosomes transmitted by triatomine bugs, Trop. Med. Parasitol. 37, 251-254.

36. Franco, A. M. R., Moreira, C. F. S., Carrera, C., Carvalho-Paes, L. E., Momen, H., Deane, M. P., Grimaldi, G. Jr (1993) Characterization of the genus Endotrypanum by isoenzymatic analysis, Mem. Inst. Oswaldo Cruz 88, 298.

37. Pacheco, R. S., Thomaz, N. \& Momen, H. (1990) kDNA crosshybridization between Endotrypanum and peripylarian Leishmania, Trans. Roy. Soc. Trop. Med. Hyg. 84, 531.

38. Vallejo, G. A., Chiari, E., Macedo, A. M. \& Pena, S. D. J. (1993) A simple laboratory method for distinguishing between Trypanosoma cruzi and Trypanosoma rangeli, Trans. Roy. Soc. Trop. Med. Hyg. 87, 165-166.

39. Schottelius, J. (1987) Neuraminidase fluorescence test for the differentiation of Trypanosoma cruzi and Trypanosoma rangeli, Trop. Med. Parasitol. 38, 323-327.

40. Reuter, G, Schauer, R., Prioli, R. \& Pereira, M. E. A. (1987) Isolation and properties of a sialidase from Trypanosoma rangeli, Glycoconjugate J. 4, 339-348.

41. Greig, S. R., Akinsehinwa, F. A., Ashall, F., Lainson, R., Shaw, J. J., Miles, M. A. \& Barker, D. C. (1989) The feasibility of discriminating between Leishmania and Endotrypanum using total parasite DNA probes, Trans. Roy. Soc. Trop. Med. Hyg. 83, 196-197.

42. Gonçanves, A. M., Nehme, N. S., Saravia, N., Segura, I. \& Morel, C. M. (1991) Schizodeme analysis with the restriction endonuclease RSA I differentiates between Trypanosoma rangeli and Trypanosoma cruzi, Mem. Inst. Oswaldo Cruz 86, $477-478$.

43. Fernandes, O., Degrave, W. \& Campbell, D. A. (1993) The mini-exon gene: a molecular marker for Endotrypanum Schaudinni, Parasitol. 107, 219-224.

44. Murthy, V. K., Dibbern, K. M. \& Campbell, D. A. (1992) PCR amplification of mini-exon genes differentiates Trypanosoma cruzi from Trypanosoma rangeli, Mol. Cell. Probes 6, 237243.

45. Novak, E. M., de Mello, M. P., Gomes, H. B. M., Galindo, I., Guevara, P., Ramirez, J. L. \& Franco da Silva, J. (1993) Repetitive sequences in the ribosomal intergenic spacer of Trypanosoma cruzi, Mol. Biochem. Parasitol. 60, 273-280. 
46. Hendricks, L. D., Wood, D. E. \& Hadjuk, M. E. (1978) Haemoflagellates: commercially available liquid media for rapid cultivation, Parasitol. 74, 309-316.

47. Schenkman, S., Robbins, E. S. \& Nussenzweig, V. (1991) Attachment of Trypanosoma cruzi to mammalian cells requires parasite energy, and invasion can be independent of the target cell cytoskeleton. Inf. Immun. 59, 645-654.

48. Udenfriend, S., Stein, S., Böhlen, P., Dairman, W., Leimgruber, W. \& Weigele, M. (1972) Fluorescamine: a reagent for assay of amino acids, peptides, proteins, and primary amines in the picomole range, Science 178, 871-872.

49. Medina-Acosta, E. \& Cross, G. A. M. (1993) Rapid isolation of DNA from trypanosomatid protozoa using a simple "miniprep" procedure, Mol. Biochem. Parasitol. 59, 327-330.

50. Brown, W. H. (1914) A note on the pathogenicity of Trypanosoma lewisi, J. Exp. Med. 19, 406-410.

51. Deane, M. P. \& Kirchner, E. (1963) Life cycle of Trypanosoma conorhini. Influence of temperature and other factors on growth and morphogenesis, J. Protozool. 10, 391-399.

52. Lopes, A. H., Iovannisci, D., Petrillo-Peixoto, M., McMahonPratt, D. \& Beverley, S, M. (1990) Evolution of nuclear DNA and the occurrence of sequences related to new small chromo- somal DNAs in the trypanosomatid genus Endotrypanum, Mol. Biochem. Parasitol. 40, 151-162.

53. Pontes de Carvalho, L. C., Tomlinson, S. \& Nussenzweig, V. (1993) Trypanosoma rangeli sialidase lacks trans-sialidase activity, Mol. Biochem. Parasitol. 62, 19-26.

54. Cavalier-Smith. T. (1993) Kingdom protozoa and its 18 phyla, Microbiol. Rev. 57, 953-994.

55. Fernandes, A. P., Nelson, K. \& Beverly, S. M. (1993) Evolution of nuclear ribosomal RNAs in kinetoplastid protozoa: perspectives on the age and origins of parasitism, Proc. Natl Acad. Sci. USA 90, 11608-11612.

56. Landweber, L. F. \& Gilbert, W. (1994) Phylogenetic analysis of RNA editing: A primitive genetic phenomenon, Proc. Natl Acad. Sci. USA 91, 918-921.

57. Maslov, D. A., Avila, H. A., Lake, J. A. \& Simpson, L. (1994) Evolution of RNA editing in kinetoplastid protozoa, Nature $368,345-348$.

58. Briones, M. R. S., Egima, C. M., Eichinger, D. \& Schenkman, S. (1994) Trans-sialidase genes expressed in mammalian forms of Trypanosoma cruzi evolved from ancestor genes expressed in insect forms of the parasite, J. Mol. Evolution, in the press.

Supplementary Material. Trans-sialidase and sialidase activities discriminate between morphologically indistinguishable trypanosomatids. The raw data used to generate Fig. 1 are available, upon request, from the Editorial Office. A total of two pages are available. 